Full length article

\title{
Tough combinatorial poly(urethane-isocyanurate) polymer networks and hydrogels synthesized by the trimerization of mixtures of NCO-prepolymers
}

\author{
P.J. Driest ${ }^{\mathrm{a}, \mathrm{b}, *}$, D.J. Dijkstra ${ }^{\mathrm{a}}$, D. Stamatialis ${ }^{\mathrm{b}}$, D.W. Grijpma ${ }^{\mathrm{b}}$ \\ a Covestro Deutschland AG, CAS-Global RED, 51373 Leverkusen, Germany \\ ${ }^{\mathrm{b}}$ Technical Medical Centre, and Faculty of Science and Technology, Department of Biomaterials Science and Technology, University of Twente, P.O. Box 217, \\ 7500 AE Enschede, the Netherlands
}

\section{A R T I C L E I N F O}

\section{Article history:}

Received 31 August 2019

Revised 14 January 2020

Accepted 17 January 2020

Available online 21 January 2020

\section{Keywords:}

Tough hydrogels

Semi-crystalline hydrogels

Polyurethanes

Combinatorial polymer networks

Structure-property-relations

\begin{abstract}
A B S T R A C T
The development of tough hydrogels is an essential but challenging topic in biomaterials research that has received much attention over the past years. By the combinatorial synthesis of polymer networks and hydrogels based on prepolymers with different properties, new materials with widely varying characteristics and unexpected properties may be identified. In this paper, we report on the properties of combinatorial poly(urethane-isocyanurate) (PUI) type polymer networks that were synthesized by the trimerization of mixtures of NCO-functionalized poly(ethylene glycol) (PEG), poly(propylene gylcol) (PPG), $\operatorname{poly}(\varepsilon$-caprolactone) (PCL) and poly(trimethylene carbonate) (PTMC) prepolymers in solution. The resulting polymer networks showed widely varying material properties.

Combinatorial PUI networks containing at least one hydrophilic PEG component showed high water uptakes of $>100 \mathrm{wt} \%$. The resulting hydrogels demonstrated elastic moduli of up to $10.1 \mathrm{MPa}$, ultimate tensile strengths of up to $9.8 \mathrm{MPa}$, elongation at break values of up to $624.0 \%$ and toughness values of up to $53.4 \mathrm{MJ} \mathrm{m}^{-3}$. These values are exceptionally high and show that combinatorial PUI hydrogels are among the toughest hydrogels reported in the literature. Also, the simple two-step synthesis and wide range of suitable starting materials make this synthesis method more versatile and widely applicable than the existing methods for synthesizing tough hydrogels. An important finding of this work is that the presence of a hydrophobic network component significantly enhances the toughness and tensile strength of the combinatorial PUI hydrogels in the hydrated state. This enhancement is the largest when the hydrophobic network component is crystallizable in nature. In fact, the PUI hydrogels containing a crystallizable hydrophobic network component are shown to be semi-crystalline in the water-swollen state. Due to their high toughness values in the water-swollen state together with their water uptake values, elastic moduli and ultimate tensile strengths, the developed hydrogels are expected to be promising materials for biomedical coating- and adhesive applications, as well as for tissue-engineering.
\end{abstract}

\section{Statement of significance}

The development of tough hydrogels is a challenging topic that has received much attention over the past years. At present, double network type hydrogels are considered state-of-the-art in the field, demonstrating toughness values of several tens of $\mathrm{MJ} \mathrm{m}^{-3}$. However, in terms of ease and versatility of the synthesis method, the possibilities are limited using a double network approach.

In this work, we present combinatorial poly(urethane-isocyanurate) type polymer networks and hydrogels, synthesized by the trimerization of mixtures of NCO-functionalized prepolymers. The resulting hydrogels demonstrate exceptionally high toughness values of up to $53 \mathrm{MJ} \mathrm{m}^{-3}$, while the synthesis method is versatile and widely applicable. This new class of hydrogels is therefore considered highly promising in the future development of load-bearing biomaterials.

(c) 2020 Acta Materialia Inc. Published by Elsevier Ltd. This is an open access article under the CC BY-NC-ND license.

(http://creativecommons.org/licenses/by-nc-nd/4.0/)
* Corresponding author at: Covestro Deutschland AG, CAS-Global R\&D, 51373 Leverkusen, Germany.
E-mail address: p.j.driest@utwente.nl (P.J. Driest). 


\section{Introduction}

During the past decades, hydrogels have played an increasingly important role in the development of biomaterials [1]. The interesting material properties of hydrogels, including a high water uptake (>100 wt\%), typical biocompatibility and physical properties resembling the natural extracellular matrix, have been exploited in a wide range of biomedical applications, such as drug-delivery, tissue engineering, injectable fillers and many more [2]. However, the poor toughness typically associated with hydrogel materials is still a drawback and has limited the exploitation of the full potential of hydrogel materials so far. As a result, promising applications as load-bearing biomaterials largely remain out of reach. Consequently, the development of tough hydrogels has received much attention over the past years [3-5].

Presently, several approaches exist for synthesizing tough hydrogels, which include (interpenetrating) double network (DN) hydrogels [3,6,7], combinatorial hydrogels [8-10], thermoplastic polyurethane (TPU) hydrogels $[11,12]$, (nano)composite hydrogels [13-15], rotaxane-based hydrogels [16] and physical interaction enhanced hydrogels (also referred to as hydrophobic association hydrogels) [17-21]. Of these, the interpenetrating double network (DN) approach (see Scheme 1) is presently the most widely-studied technique leading to the best-performing materials [7,22-28]. Although the double network approach has its advantages in terms of mechanical performance, there are still some drawbacks there. These are mostly found in terms of practicality and applicability. For example, typically a multi-step sequential crosslinking-swelling-crosslinking procedure is needed to obtain the interpenetrating double network structure that is required to achieve the desired material properties [29]. In general, in terms of type and molecular weight of possible starting materials and the resulting control over the final material properties, the range of possibilities is considered limited in a DN approach.

An alternative approach for synthesizing tough hydrogels is based on the combinatorial (photo)crosslinking of mixtures of hydrophobic and hydrophilic (meth)acrylate-functionalized prepolymers (see Scheme 1) [8-10]. Although these combinatorial hydrogels did not yet demonstrate the same level of toughness or tensile strength as the best-performing DN hydrogels, they did match those of various biological materials, most notably cartilage [10]. Meanwhile, the relative simplicity of the synthesis method, the wide range of possible starting materials and the range and control over the final material properties are a clear advantage of a combinatorial synthesis approach [30].

We recently developed a method to synthesize homopolymeric well-defined poly(urethane-isocyanurate) (PUI) type polymer networks, that is based on the trimerization of NCO-functionalized prepolymers [31]. These networks, similar to photocrosslinked combinatorial ones, are readily synthesized and the use of a wide range of starting materials (i.e. any di- or polyol) and a wide range and control over final material properties are possible. Interestingly, it was found that the hydrophilic homopolymeric PUI materials based on poly(ethylene glycol) (PEG) prepolymers

a) Combinatorial Trimerization of NCO-functionalized Prepolymers

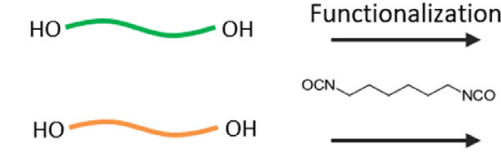

HO $\mathrm{OH}$ Polymeric diol 1

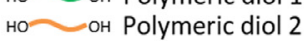

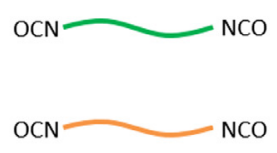

NCO-functionalized Prepolymers

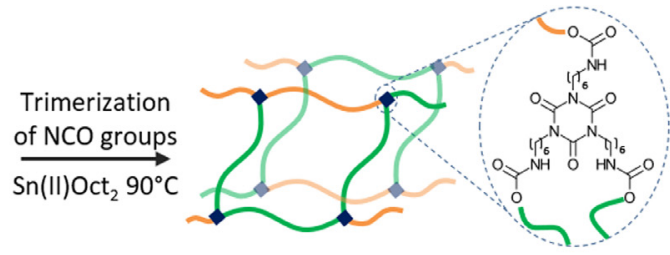

Combinatorial Poly(urethaneisocyanurate) Network

b) Interpenetrating Double Network Formation by Sequential Crosslinking

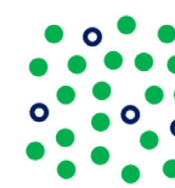
$\longrightarrow$

- Monomer System 1

- Photoinitiator
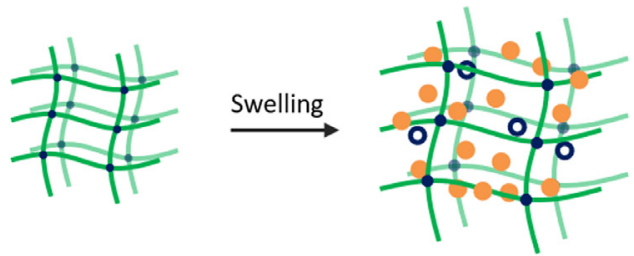

Network 1

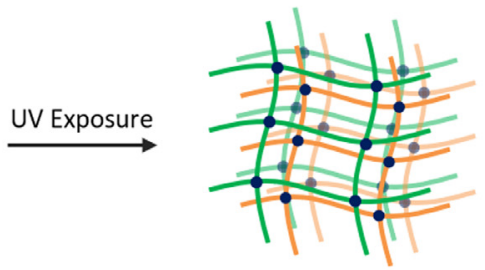

Interpenetrating Double Network

c) Combinatorial Photocrosslinking of (Meth)acrylate-functionalized Prepolymers

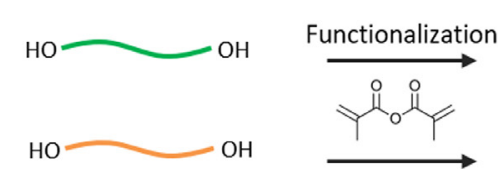

$\mathrm{HO}$ OH Polymeric diol 1

$\mathrm{HO}-\mathrm{OH}$ Polymeric diol 2

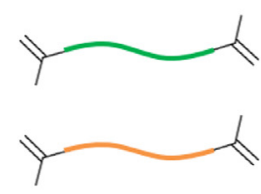

(Meth)acrylate-functionalized Prepolymers

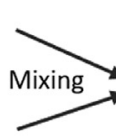

$\stackrel{\text { UV Exposure }}{\longrightarrow}$

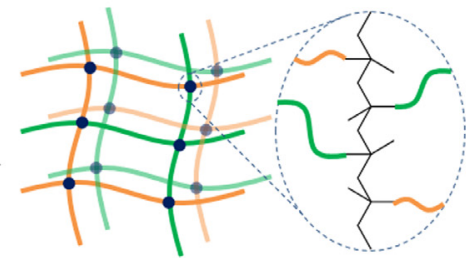

Combinatorial

Photocrosslinked Network

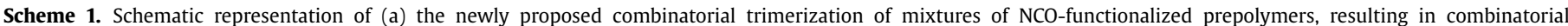

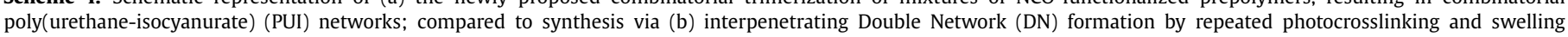
steps and (c) the combinatorial photocrosslinking of mixtures of (meth)acrylate-functionalized prepolymers. 
demonstrated relatively high mechanical strength and toughness in the hydrated state for homopolymeric networks [31].

In this paper, we investigate whether combinatorial, heteropolymeric PUI networks and hydrogels with high mechanical strength and toughness in the hydrated state can be synthesized by the trimerization of mixtures of NCO-prepolymers in solution, as illustrated in Scheme 1. Since we focus on gels suitable for biomedical applications, we use combinations of several hydrophilic and hydrophobic polymeric diols that are often applied in the biomedical field, including poly(ethylene glycol) (PEG), poly(propylene gylcol) (PPG), poly( $\varepsilon$-caprolactone) (PCL), and poly(trimethylene carbonate) (PTMC). In the molecular weight range used, PEG is a crystallizable hydrophilic polymer with a glass transition temperature $\left(\mathrm{T}_{\mathrm{g}}\right)$ between $-24^{\circ} \mathrm{C}$ and $-37^{\circ} \mathrm{C}$ and a peak melting temperature $\left(\mathrm{T}_{\mathrm{m}}\right)$ between $58^{\circ} \mathrm{C}$ and $66^{\circ} \mathrm{C}[32,33]$. PCL is a crystallizable hydrophobic polymer with a $T_{g}$ and $T_{m}$ of approximately $-60{ }^{\circ} \mathrm{C}$ and $59^{\circ} \mathrm{C}$, respectively, while PPG and PTMC are amorphous hydrophobic polymers with $\mathrm{T}_{\mathrm{g}} \mathrm{s}$ of approximately $-60{ }^{\circ} \mathrm{C}$ and $-15^{\circ} \mathrm{C}$, respectively [34-36].

\section{Experimental details}

\subsection{Materials and methods}

Poly(ethylene glycol)s $\left(\overline{M_{n}} 4\right.$ and $\left.10 \mathrm{~kg} / \mathrm{mol}\right)$, stannous octoate $\left(\mathrm{Sn}(\mathrm{II}) \mathrm{Oct}_{2}\right), 1,6$-hexanediol and propylene carbonate were purchased from Sigma-Aldrich. Poly( $\varepsilon$-caprolactone)s $\left(\overline{M_{n}} 4\right.$ and $8 \mathrm{~kg} / \mathrm{mol}$ ) were kindly supplied by Perstorp Chemicals $\mathrm{GmbH}$. Trimethylene carbonate (TMC) was kindly supplied by ForYou Medical Devices Co Ltd. Hexamethylene diisocyanate (HDI) and poly(propylene glycols) $\left(\overline{M_{n}} 4\right.$ and $8 \mathrm{~kg} / \mathrm{mol}$ ) were supplied by Covestro Deutschland AG. All other chemicals were purchased from Sigma-Aldrich.

All reactions were conducted under a nitrogen atmosphere using standard Schlenck-line techniques. Differential scanning calorimetry (DSC) measurements were performed under nitrogen on ca. $10 \mathrm{mg}$ samples on a Perkin-Elmer Calorimeter DSC-7. Samples in the dry state were measured in 2 heating runs from $-100^{\circ} \mathrm{C}$ to $+150^{\circ} \mathrm{C}$ with a heating rate of $20^{\circ} \mathrm{C} / \mathrm{min}$ and a cooling rate of $20^{\circ} \mathrm{C} / \mathrm{min}$. Samples in the hydrated state were measured in a high-pressure DSC-pan in 1 heating run from $+5^{\circ} \mathrm{C}$ to $+80^{\circ} \mathrm{C}$ with a heating rate of $20^{\circ} \mathrm{C} / \mathrm{min}$. The glass transition temperature $(\mathrm{s})\left(\mathrm{T}_{\mathrm{g}}\right)$, peak melting temperature $(\mathrm{s})\left(\mathrm{T}_{\mathrm{m}, \mathrm{p}}\right)$ and melting enthalpy value(s) $\left(\Delta H_{m}\right.$, obtained from the area under the melting peak) were determined based on the last heating run. NMR-spectra were collected on a Bruker Advance III-700 in the specified solvent. FTIR-spectra were recorded on a Bruker FTIR Spectrometer Tensor II with Platinum-ATR-unit with diamond crystal. Size exclusion chromatography (SEC) was performed according to DIN 556721:2016-03, on 4 PSS SDV Analytical columns $(2 \times 100 \AA$, $5 \mu \mathrm{m}$; $2 \times 1000 \AA, 5 \mu \mathrm{m})$ using an Agilent 1100 Series pump and an Agilent 1200 Series UV Detector $(230 \mathrm{~nm})$ with tetrahydrofuran as the elution solvent at $40^{\circ} \mathrm{C}$ and $1.00 \mathrm{~mL} / \mathrm{min}$. Residual monomeric diisocyanate contents were determined by gas chromatography (GC) according to DIN EN ISO 10283 on an Agilent Technologies $6890 \mathrm{~N}$ system using a $15.0 \mathrm{~m}$ DB17 column and tetradecane as an internal standard. Tensile tests were performed in triplicate at room temperature using a Zwick Z0.5 tensile tester equipped with a $500 \mathrm{~N}$ load cell at $200 \mathrm{~mm} / \mathrm{min}$. with a grip-to-grip separation of $35 \mathrm{~mm}$ on strips of approximately $60 \times 4 \times 0.5 \mathrm{~mm}$ cut from a cured film. Elastic moduli and strain values were derived from the initial gripto-grip separation and are therefore indicative only. The toughness values of the materials were calculated from the work at break value, normalized for the dimensions of the specimen.

For swelling measurements, three samples measuring approximately $10 \times 20 \times 0.5 \mathrm{~mm}$ were cut from a cured, extracted and dried film and weighed (denoted $m_{i}$ ). Each sample was then swollen in excess water for at least $24 \mathrm{~h}$, blotted dry and weighed again in the hydrated state (denoted $m_{s}$ ). The water uptake was defined as:

water uptake $=\frac{m_{s}-m_{i}}{m_{i}} \times 100 \%$

\subsection{Synthesis of an $\mathrm{OH}$-functional PTMC polymeric diol}

A PTMC polymeric diol was synthesized by the previously reported ring-opening polymerization of trimethylene carbonate, using 1,6-hexandiol as the initiator and $\mathrm{Sn}(\mathrm{II}) \mathrm{Oct}_{2}$ as the catalyst [8]. Under dry conditions, $101.1 \mathrm{~g}(0.99 \mathrm{~mol})$ of trimethylene carbonate was weighed into a dried and nitrogen-secured $250 \mathrm{~mL} 3$-neck flask. Next, $2.93 \mathrm{~g}$ (24.8 mmol) of 1,6-hexanediol was added and the mixture was heated to $130^{\circ} \mathrm{C}$. Next, $55 \mathrm{mg}$ of $\mathrm{Sn}(\mathrm{II}) \mathrm{Oct}_{2}$ was added and the mixture was kept at $130^{\circ} \mathrm{C}$ for $40 \mathrm{~h}$. The resulting product was collected as a viscous, transparent, colorless resin and analyzed by SEC and ${ }^{1} \mathrm{H}$ NMR $\left(600 \mathrm{MHz}, \mathrm{CDCl}_{3},\right): \delta=4.00(160 \mathrm{H}$, brs), 3.39 ( $4 \mathrm{H}$, brs), 1.64 ( $80 \mathrm{H}$, brs), 1.35 (4H, brs), 1.04 (4H, brs) ppm.

\subsection{Synthesis of NCO-functionalized prepolymers}

All polymeric diols were dried prior to use by azeotropic distillation in toluene, which was subsequently removed under reduced pressure. In a typical experiment, $0.25 \mathrm{~g}$ of dibutylphosphate was added to $100 \mathrm{~g}$ of dried polymeric diol, which was kept in the melt using a heat gun where applicable. This mixture was added dropwise to HDI kept at $100^{\circ} \mathrm{C}$, using a molar ratio of $\mathrm{NCO}: \mathrm{OH}$ of $15: 1$, and the resulting mixture was subsequently kept at $100^{\circ} \mathrm{C}$ for $3 \mathrm{~h}$. In the case of PPG polymeric diols, the procedure was performed at $120^{\circ} \mathrm{C}$ and kept at $120^{\circ} \mathrm{C}$ for $6 \mathrm{~h}$. The resulting mixture was then transferred dropwise into a cylindrical glass shortpath thin-film evaporator equipped with Teflon wipers with a volume of approximately $500 \mathrm{~mL}$, which was operated at a reduced pressure of $1 \cdot 10^{-2}$ mbar at $140{ }^{\circ} \mathrm{C}$. All functionalized prepolymers were collected as clear, colorless, viscous resins, of which the PEGand PCL-based resins crystallized upon cooling to room temperature. Products were analyzed by SEC, GC and ${ }^{1} \mathrm{H}$ NMR $(700 \mathrm{MHz}$, $\mathrm{C}_{6} \mathrm{D}_{6}$, representative data for PEG-4k): $\delta=4.60(2 \mathrm{H}, \mathrm{brs}), 4.26(4 \mathrm{H}$, t), $3.50(410 \mathrm{H}, \mathrm{m}), 2.97(4 \mathrm{H}, \mathrm{q}), 2.56(4 \mathrm{H}, \mathrm{t}), 1.12(4 \mathrm{H}, \mathrm{t}), 1.02(4 \mathrm{H}$, t), $0.88(8 \mathrm{H}, \mathrm{m}) \mathrm{ppm}$.

2.4. Synthesis of combinatorial poly(urethane-isocyanurate) networks by the trimerization of mixtures of NCO-functionalized prepolymers in solution

Combinatorial poly(urethane-isocyanurate) networks were synthesized in analogy to a previously reported procedure [31], with slight modifications. In a typical experiment, $4 \mathrm{~g}$ of propylene carbonate was weighed into a polypropylene cup. Next, the respective NCO-prepolymers were added in the melt in the reported weight ratios, always totaling $4 \mathrm{~g}$. The mixture was then kept under nitrogen under continuous stirring, until a macroscopically homogenous solution was formed. Whenever crystallization was observed, the mixture was gently heated to $50-60^{\circ} \mathrm{C}$ until the mixture was liquid again. The mixture was subsequently degassed by gently applying a reduced pressure of ca. 1-10 mbar until no more bubbles were observed, whereby it was observed that no residue was built up in the cooling trap of the vacuum pump. Next, ca. $60 \mathrm{mg}$ of $\mathrm{Sn}(\mathrm{II}) \mathrm{Oct}_{2}$ (corresponding to ca. $0.75 \mathrm{wt} \%$ relative to the solution) was added. After mixing for $15 \mathrm{~s}$ in a Hauschild Speedmixer DAC150FVZ, the mixture was brought into a mold consisting of a $0.5 \mathrm{~mm}$-thick polycarbonate frame clamped between two silanized glass plates measuring $20 \times 10 \mathrm{~cm}$ and kept at $90{ }^{\circ} \mathrm{C}$ for $48 \mathrm{~h}$. Unless reported otherwise, all reaction mixtures were optically transparent within $15 \mathrm{~min}$ after heating to $90^{\circ} \mathrm{C}$. Cured samples were 
Table 1

Characterization of the NCO-functionalized prepolymers. $\mathrm{M}_{\mathrm{n}}$ represents the molecular weight of the NCO-functionalized prepolymer as calculated from the respective ${ }^{1} \mathrm{H}$ NMR spectrum; Đ represents the polydispersity index of the NCOfunctionalized prepolymer; and Residual HDI Content represents the mass percentage of residual free (unreacted) HDI in the NCO-functionalized prepolymer after thin-film evaporation.

\begin{tabular}{llll}
\hline NCO-functionalized prepolymer & $\mathrm{M}_{\mathrm{n}}[\mathrm{kg} / \mathrm{mol}]$ & $\oplus$ [dimensionless] & Residual HDI content [wt\%] \\
\hline PEG-4k-diNCO & 3.9 & 1.17 & $<0.01$ \\
PEG-10k-diNCO & 9.4 & 1.20 & 0.09 \\
PCL-4k-diNCO & 3.9 & 1.30 & 0.21 \\
PCL-8k-diNCO & 7.8 & 1.43 & 0.17 \\
PPG-4k-diNCO & 4.1 & 1.30 & 0.02 \\
PPG-8k-diNCO & 8.0 & 1.13 & $<0.01$ \\
PTMC-4k-diNCO & 4.1 & 1.44 & 0.98 \\
\hline
\end{tabular}

collected as flexible, non-sticky films, which were macroscopically homogeneous, unless reported otherwise. The films were subsequently extracted by swelling in an excess of acetone for $12-24 \mathrm{~h}$ while periodically refreshing the solvent. Typically, 6-8 films were extracted simultaneously using $3 \times 500 \mathrm{~mL}$ acetone. Next, $5 \mathrm{~L}$ of $\mathrm{n}$ hexane was slowly dripped into the $500 \mathrm{~mL}$ of acetone over the course of $24 \mathrm{~h}$ which was allowed to overflow, thereby slowly exchanging the acetone with n-hexane. During this process, the films slowly contracted. The resulting films were then dried, first in air and subsequently in vacuum, and analyzed by FTIR, swelling, tensile testing and DSC experiments as described. The remainder of each film was then swollen in an excess of water for at least $24 \mathrm{~h}$, and analyzed in the water-swollen state by tensile testing and DSC experiments.

\section{Results and discussion}

\subsection{Synthesis of NCO-functionalized prepolymers}

All polymeric diols were functionalized using hexamethylene diisocyanate (HDI), in a procedure analogous to the one described before [31]. In the case of the PPG polymeric diols, the reaction temperature and time were increased to $120^{\circ} \mathrm{C}$ and $6 \mathrm{~h}$, respectively. This was done because the uncatalyzed urethanization reaction typically occurs less readily for secondary alcohols than for primary alcohols. Since as-received commercial polymeric diols may contain traces of base, working under slightly acidic conditions was always ensured by adding a small amount of dibutyl phosphate (DBP) to the reaction mixture prior to reaction. This was done in order to prevent any undesired side-reactions involving the isocyanates, such as isocyanurate (trimer), uretdione (dimer) or allophanate formation.

Based on ${ }^{1} \mathrm{H}$ NMR, it was confirmed that the functionalization of all polymeric diols with HDI succeeded selectively and quantitatively. No side products were observed in the ${ }^{1} \mathrm{H}$ NMR spectra. From the ${ }^{1} \mathrm{H}$ NMR-spectra, the average molecular weights of the functionalized prepolymers were calculated. In order to synthesize functionalized prepolymers with a narrow molecular weight distribution, a large molar excess of HDI of 15:1 was used. Using SEC, it was shown that the polydispersity index $\left(\nexists=\overline{M_{w}} / \overline{M_{n}}\right)$ of the prepolymers after functionalization was relatively low and was always $<1.5$. Finally, it was confirmed by GC that the unreacted excess of monomeric diisocyanate was effectively removed by short-path thin-film evaporation. This resulted in functionalized prepolymers with a residual HDI content lower than $1 \mathrm{wt} \%$ in all cases. The characteristics of all functionalized prepolymers are reported in Table 1.

\subsection{Synthesis of combinatorial poly(urethane-isocyanurate) networks by the trimerization of mixtures of NCO-functionalized prepolymers in solution}

Various combinatorial poly(urethane-isocyanurate) (PUI) polymer networks were synthesized by the trimerization of mixtures of NCO-functionalized prepolymers. The synthesis approach was similar to the one reported previously for single-network PUIs, with the main difference that here the crosslinking reaction was performed in solution instead of in bulk [31]. This was done because typically NCO-prepolymers of different nature are not homogeneously miscible as such. Propylene carbonate was selected as a high-boiling aprotic inert solvent in which the combinatorial trimerization reactions could be carried out at a concentration of $50 \mathrm{wt} \%$. In most cases, the 50wt\% solutions of combined NCOfunctionalized prepolymers in propylene carbonate were stable, homogeneous and transparent at room temperature. In some cases, the prepolymer mixture was slightly turbid at room temperature, indicating a certain degree of phase separation. Typically, these prepolymer solutions turned transparent and homogeneous within 15 min after addition of the catalyst and heating to $90{ }^{\circ} \mathrm{C}$ and remained transparent throughout the trimerization reaction. In a few cases involving PPG prepolymers, macroscopic phase separation into domains with a size of ca. 0.1-1 mm was observed during the trimerization reaction. The resulting polymer films were heterogeneous after crosslinking. These films were not characterized. Whenever this was the case, it is indicated in the table(s) where the material properties are reported.

To obtain the networks in the dry state after the trimerization reaction was completed, the high boiling propylene carbonate was extracted from the polymer networks using acetone. In order to subsequently de-swell the polymer films in a controlled manner, the acetone was slowly exchanged for n-hexane over the course of $24 \mathrm{~h}$. Since n-hexane is a non-solvent for all the network components used in this study, this solvent-exchange-process resulted in the contraction of the networks. Typically, the films also turned opaque during this process. This indicates that (micro)phase separation of the different network components took place within the polymer networks upon de-swelling.

After drying, the completion of the trimerization reaction was confirmed in all cases by FTIR. This was done by confirming the disappearance of the absorption peak in the range of $2270 \mathrm{~cm}^{-1}$ associated with the NCO groups. Simultaneously, the appearance of an extra carbonyl peak in the range of $1690 \mathrm{~cm}^{-1}$ associated with the aliphatic isocyanurate (trimer) was confirmed, in analogy to what was reported previously [31]. It was observed that the polymer films remained opaque upon drying, indicating phase separation.

\subsection{Material properties of combinatorial poly(urethane-isocyanurate) networks in the dry state}

The thermal and tensile material properties of the polymer networks in the dry state are reported in Table 2 . In the tensile tests, the networks displayed widely varying mechanical properties, ranging from relatively stiff to more flexible and ductile elastomeric behavior. A selection of tensile stress-strain diagrams is shown in Fig. 1a. The wide range of mechanical properties is 
Table 2

Characterization of combinatorial PUI networks in the dry state. The prepolymers present in the networks (indicated by a gray box) are present in equal weight percentages. Numbers in parentheses represent standard deviations.

\begin{tabular}{|c|c|c|c|c|c|c|c|c|c|c|c|c|c|c|}
\hline$\#$ & & & $\begin{array}{l}\mathrm{N} \\
\text { Con }\end{array}$ & $\begin{array}{l}\text { two } \\
\text { apon }\end{array}$ & $\begin{array}{l}\text { rk } \\
\text { hent }\end{array}$ & & & & Thermal & & & & & \\
\hline 旁 & $\begin{array}{l}\text { 守 } \\
\text { 㟧 } \\
\text { a }\end{array}$ & 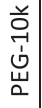 & 守 & 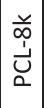 & $\begin{array}{l}\text { 音 } \\
\dot{0} \\
\text { ㅁ }\end{array}$ & $\begin{array}{l}\text { 㒸 } \\
0 \\
0 \\
\frac{0}{\alpha}\end{array}$ & 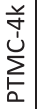 & $\begin{array}{l}\mathrm{T}_{\mathrm{g}, \mathrm{dry}} \\
{\left[{ }^{\circ} \mathrm{C}\right]}\end{array}$ & $\begin{array}{c}\mathrm{T}_{\mathrm{m}, \mathrm{p}, \mathrm{dry}} \\
{\left[{ }^{\circ} \mathrm{C}\right]}\end{array}$ & $\begin{array}{c}\Delta \mathrm{H}_{\mathrm{m}} \\
{\left[\mathrm{J} \cdot \mathrm{g}^{-1}\right]}\end{array}$ & $\begin{array}{c}\mathrm{E}_{\text {mod,dry }} \\
\text { [MPa] }\end{array}$ & $\begin{array}{c}\sigma_{\mathrm{b}, \mathrm{dry}} \\
{[\mathrm{MPa}]}\end{array}$ & $\begin{array}{c}\varepsilon_{\mathrm{b}, \mathrm{dry}} \\
{[\%]}\end{array}$ & $\begin{array}{l}\mathrm{W}_{\text {tensile,dry }} \\
{\left[\mathrm{MJ} \cdot \mathrm{m}^{-3}\right]}\end{array}$ \\
\hline 1 & & & & & & & & -49.9 & 55.6 & 103.6 & $\begin{array}{c}73.6 \\
(-)^{a}\end{array}$ & $\begin{array}{c}17.5 \\
(-)^{a}\end{array}$ & $\begin{array}{c}864.5 \\
(-)^{a}\end{array}$ & $\begin{array}{c}72.79 \\
(-)^{a}\end{array}$ \\
\hline 2 & & & & & & & & -58.8 & 39.5 & 62.4 & $\begin{array}{l}65.0 \\
(-)^{a}\end{array}$ & $\begin{array}{c}23.8 \\
(-)^{a}\end{array}$ & $\begin{array}{c}1305 \\
(-)^{\mathrm{a}}\end{array}$ & $\begin{array}{c}150.4 \\
(-)^{\mathrm{a}}\end{array}$ \\
\hline 3 & & & & & & & & -58.4 & $\begin{array}{l}\text { 1) } 46.2 \\
\text { 2) } 50.6\end{array}$ & $\begin{array}{l}\text { 1) } 13.2 \\
\text { 2) } 57.3\end{array}$ & $\begin{array}{l}184.7 \\
(19.4)\end{array}$ & $\begin{array}{l}19.5 \\
(0.5)\end{array}$ & $\begin{array}{l}871.2 \\
(26.9)\end{array}$ & $\begin{array}{c}103.0 \\
(3.2)\end{array}$ \\
\hline $4^{b}$ & & & & & & & & $-b$ & $-\mathrm{b}$ & $-{ }^{b}$ & $-^{b}$ & $-b$ & $-b$ & $-b$ \\
\hline $5^{b}$ & & & & & & & & $-^{b}$ & $-^{b}$ & $-b$ & $-{ }^{b}$ & $-b$ & $-b$ & $-b$ \\
\hline 6 & & & & & & & & $-^{c}$ & $-^{c}$ & $-{ }^{c}$ & $\begin{array}{c}3.2 \\
(0.8)\end{array}$ & $\begin{array}{c}1.5 \\
(0.2)\end{array}$ & $\begin{array}{l}107.2 \\
(23.9)\end{array}$ & $\begin{array}{c}1.06 \\
(0.28)\end{array}$ \\
\hline 7 & & & & & & & & -55.3 & 54.5 & 76.4 & $\begin{array}{l}124.9 \\
(30.4) \\
\end{array}$ & $\begin{array}{l}20.1 \\
(1.3) \\
\end{array}$ & $\begin{array}{c}1025 \\
(40.5)\end{array}$ & $\begin{array}{c}112.7 \\
(3.3)\end{array}$ \\
\hline 8 & & & & & & & & -58.4 & 54.6 & 81.6 & $\begin{array}{c}221.1 \\
(46.7)^{d}\end{array}$ & $\begin{array}{c}16.0 \\
(0.7)^{d}\end{array}$ & $\begin{array}{c}555.4 \\
(22.7)^{d}\end{array}$ & $\begin{array}{c}60.8 \\
(0.3)^{d}\end{array}$ \\
\hline $9^{b}$ & & & & & & & & $--^{b}$ & $-{ }^{b}$ & $-{ }^{b}$ & $-{ }^{b}$ & $-{ }^{b}$ & $-{ }^{b}$ & $-{ }^{b}$ \\
\hline $10^{b}$ & & & & & & & & $-b$ & $-{ }^{b}$ & $-{ }^{b}$ & $-{ }^{b}$ & $-{ }^{b}$ & $-{ }^{b}$ & $-{ }^{b}$ \\
\hline 11 & & & & & & & & -45.7 & 42.6 & 50.2 & $\begin{array}{l}34.6 \\
(7.4)\end{array}$ & $\begin{array}{c}4.1 \\
(0.6)\end{array}$ & $\begin{array}{l}255.8 \\
(65.0)\end{array}$ & $\begin{array}{c}8.65 \\
(1.91)\end{array}$ \\
\hline 12 & & & & & & & & -57.8 & 53.5 & 53.6 & $\begin{array}{l}105.4 \\
(29.2)\end{array}$ & $\begin{array}{l}25.1 \\
(8.5)\end{array}$ & $\begin{array}{c}586.5 \\
(108.5)\end{array}$ & $\begin{array}{c}78.2 \\
(24.6)\end{array}$ \\
\hline $13^{\mathrm{b}}$ & & & & & & & & $-^{b}$ & $-^{b}$ & $--^{b}$ & $-{ }^{b}$ & $-{ }^{b}$ & $-{ }^{b}$ & $-{ }^{b}$ \\
\hline 14 & & & & & & & & -67.1 & 36.2 & 24.2 & $\begin{array}{l}15.6 \\
(2.2)\end{array}$ & $\begin{array}{c}5.2 \\
(0.1) \\
\end{array}$ & $\begin{array}{l}339.9 \\
(13.9) \\
\end{array}$ & $\begin{array}{l}11.03 \\
(0.70) \\
\end{array}$ \\
\hline 15 & & & & & & & & -19.7 & 37 & 34 & $\begin{array}{l}43.7 \\
(2.1)\end{array}$ & $\begin{array}{c}5.6 \\
(0.4) \\
\end{array}$ & $\begin{array}{l}198.5 \\
(18.4)\end{array}$ & $\begin{array}{c}6.95 \\
(0.65) \\
\end{array}$ \\
\hline 16 & & & & & & & & -64.3 & 41 & 26.7 & $\begin{array}{l}21.6 \\
(1.2)\end{array}$ & $\begin{array}{c}4.7 \\
(0.3) \\
\end{array}$ & $\begin{array}{l}170.9 \\
(24.1)\end{array}$ & $\begin{array}{c}5.84 \\
(0.86)\end{array}$ \\
\hline 17 & & & & & & & & -64.7 & 50.4 & 35 & $\begin{array}{l}42.3 \\
(1.8) \\
\end{array}$ & $\begin{array}{l}13.0 \\
(0.8) \\
\end{array}$ & $\begin{array}{l}520.3 \\
(36.9) \\
\end{array}$ & $\begin{array}{l}36.91 \\
(3.23) \\
\end{array}$ \\
\hline 18 & & & & & & & & $\begin{array}{l}\text { 1) }-56.1 \\
\text { 2) }-18.1\end{array}$ & 47.3 & 27.8 & $\begin{array}{l}16.4 \\
(0.8)\end{array}$ & $\begin{array}{c}3.2 \\
(0.1)\end{array}$ & $\begin{array}{l}47.2 \\
(2.6) \\
\end{array}$ & $\begin{array}{c}1.01 \\
(0.08)\end{array}$ \\
\hline $19^{\mathrm{b}}$ & & & & & & & & $-b$ & $-{ }^{b}$ & $-b$ & $-b$ & $-b$ & $-b$ & $-\mathrm{b}$ \\
\hline 20 & & & & & & & & $\begin{array}{l}\text { 1) }-63.9 \\
\text { 2) }-19.5 \\
\end{array}$ & c c & $-_{-}^{c}$ & $\begin{array}{c}1.5 \\
(0.2)\end{array}$ & $\begin{array}{c}0.5 \\
(0.1) \\
\end{array}$ & $\begin{array}{c}67.5 \\
(12.8) \\
\end{array}$ & $\begin{array}{c}0.24 \\
(0.06) \\
\end{array}$ \\
\hline
\end{tabular}

${ }^{\mathrm{a}} n=1$.

${ }^{\mathrm{b}}$ macroscopic phase separation observed during crosslinking, resulting in a heterogeneous polymer film.

${ }^{\mathrm{c}}$ not observed.

$\mathrm{d} n=2$.

best indicated by the elastic moduli measured in the dry state $\left(\mathrm{E}_{\text {mod,dry }}\right)$, which covered a range of values from $1.5 \mathrm{MPa}$ to 221.1 MPa. Also the ultimate tensile strengths $\left(\sigma_{\mathrm{b}, \mathrm{dry}}\right)$ and elongation at break values $\left(\varepsilon_{\mathrm{b}, \mathrm{dry}}\right)$ varied widely and ranged from $0.5 \mathrm{MPa}$ to $25.1 \mathrm{MPa}$ and from $47.2 \%$ to $1305 \%$, respectively. Starting from only 4 different types of common polymeric diols, this shows that the synthesis method allows for the production of a wide variety of materials. The toughness values of the networks ( $\left.\mathrm{W}_{\text {tensile,dry }}\right)$ were calculated from the work at break values and are reported

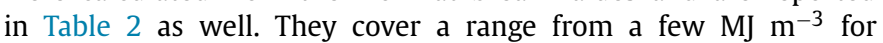
the weaker networks up to $150 \mathrm{MJ} \mathrm{m}^{-3}$ for the toughest network. In the dry state, no direct correlation between the molecular weight of the prepolymers and the mechanical properties of the networks could be observed. The expected reason for this is that the differences in molecular weight of the prepolymers also affect the crystallinity of the networks, which will be discussed below.

Analogous to the single-network PUIs reported previously, the thermal properties of the combinatorial networks (reported in
Table 2) are dictated by the thermal properties of the respective polymer network components present in the network. It was found that whenever a crystallizable prepolymer was present in the combinatorial PUI network, a corresponding crystallization peak was observed in the DSC curve of the network. In fact, in the cases where two crystallizable prepolymer components of a different nature were present in one combinatorial network (networks 2, 3, 7 and 8), an overlapping double melting peak was observed in the DSC measurements of the network. In the case of network 3, of which the DSC curves are shown as an example in Fig. 1b, even two separate melting- and crystallization peaks were observed. At this point it is worthwhile to note that all solutions containing PEG and PCL prepolymers were optically transparent and homogeneous throughout the crosslinking reaction. It is therefore expected that the prepolymers were homogeneously mixed at the molecular level during crosslinking. The fact that separate melting peaks are then observed for the covalently crosslinked combinatorial polymer network in the dry state is noteworthy. This indicates that the two separate crystallizable network 

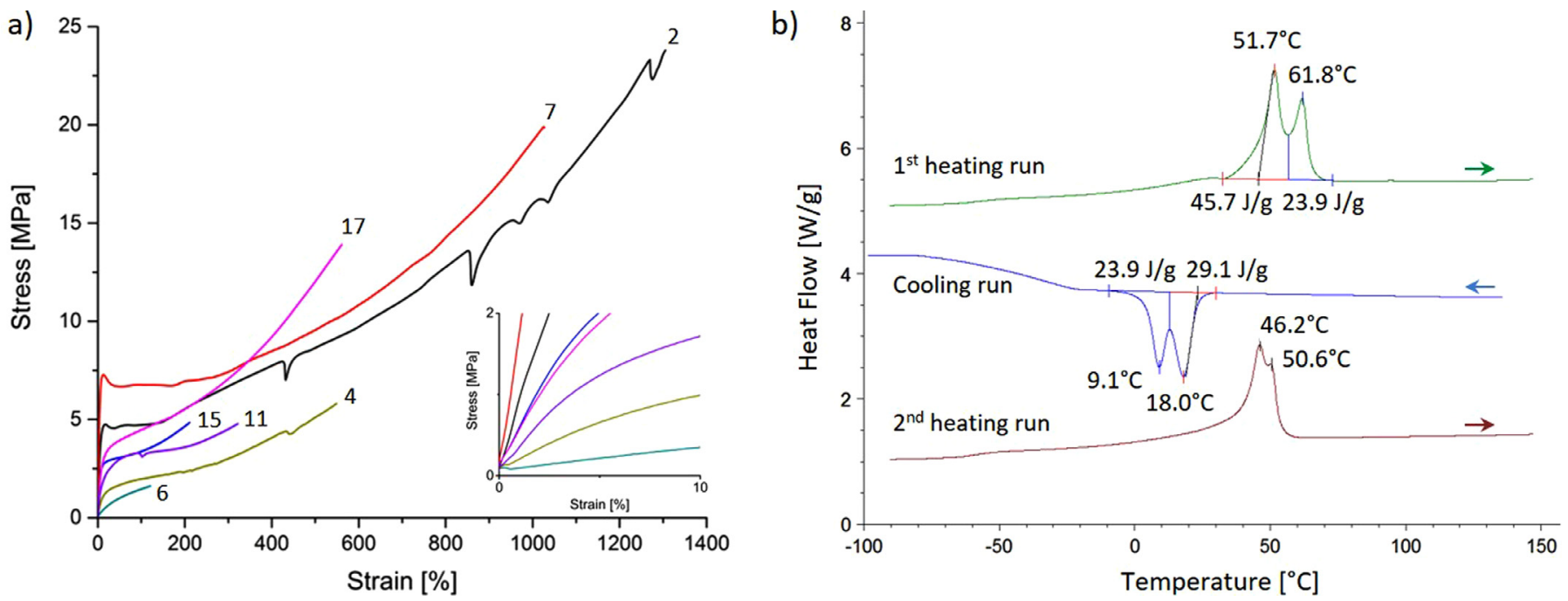

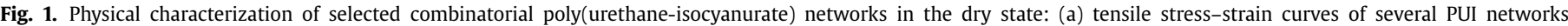

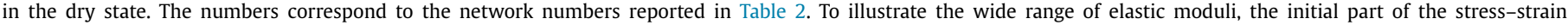

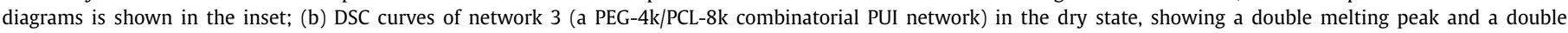
crystallization peak in both heating runs and in the cooling run, respectively.

components of different nature were able to crystallize within the same combinatorial polymer network.

\subsection{Mechanical properties of combinatorial \\ poly(urethane-isocyanurate) networks in the hydrated state}

All combinatorial PUI networks were characterized by swelling in water. The resulting water uptake values of the materials are reported in Table 3. As expected, all networks containing at least one hydrophilic PEG component (samples $1 \mathrm{~W}-11 \mathrm{~W}$, marked in blue in Table 3) strongly swelled in water and can therefore be classified as hydrogels. These materials all demonstrated water uptakes $>100$ wt\%. Samples that did not contain any hydrophilic PEG component (samples 12W-20W) were hydrophobic in nature and therefore barely swelled in water. These networks all demonstrated water uptakes $<2.5 \mathrm{wt} \%$ and are not considered hydrogels. Generally, it was found that water uptake of the networks was dictated by the molecular weight and nature of the prepolymers present in the network. Networks based on lower molecular weight prepolymers, having a denser network structure, typically demonstrated lower water uptake values than their higher molecular weight counterparts.

The mechanical properties of all combinatorial networks in the hydrated state are reported in Table 3 . The mechanical properties of the hydrophobic networks (networks 12W-20W) did not change considerably compared to the dry state and will not be further discussed. The mechanical properties of the networks classified as hydrogels (networks $1 \mathrm{~W}-11 \mathrm{~W}$ ) on the other hand changed considerably compared to the dry state, most notably by a strong decrease in elastic modulus, ultimate tensile strength and elongation at break. These hydrogels demonstrated elastic moduli in the hydrated state $\left(\mathrm{E}_{\text {mod,wet }}\right)$ ranging from $0.5 \mathrm{MPa}$ to $10.1 \mathrm{MPa}$. The ultimate tensile strengths of the hydrogels in the hydrated state $\left(\sigma_{\mathrm{b}, \text { wet }}\right)$ ranged from $0.03 \mathrm{MPa}$ to $7.7 \mathrm{MPa}$, increasing up to $9.8 \mathrm{MPa}$ for the best-performing sample of network $2 \mathrm{~W}$. The elongation at break values in the hydrated state $\left(\varepsilon_{\mathrm{b} \text {,wet }}\right)$ ranged from $82.2 \%$ to $624 \%$. The toughness values of the hydrogels in the hydrated state $\left(\mathrm{W}_{\text {tensile,wet }}\right)$ were calculated from the work at break values and ranged from $0.02 \mathrm{MJ} \mathrm{m}^{-3}$ to $33.2 \mathrm{MJ} \mathrm{m} \mathrm{m}^{-3}$, increasing up to $53.4 \mathrm{MJ} \mathrm{m}^{-3}$ for the best-performing sample of network $2 \mathrm{~W}$. These values are considered exceptionally high for hydrogels in the hydrated state for the given amounts of water content. The tensile stress-strain diagrams of several PUI hydrogels in the hydrated state are shown in Fig. 2a. With the exception of sample $2 \mathrm{~W}$, the hydrogels synthesized from higher molecular weight prepolymers typically demonstrated higher elongation at break values but lower ultimate tensile strengths than their low molecular weight counterparts.

Notably, ultimate tensile strength values of several MPa and toughness values in the range of several tens of $\mathrm{MJ} \mathrm{m}^{-3}$ are comparable to the toughest double network (DN) hydrogels that are well-known from the literature $[6,23,25,28,37,38]$. Interestingly, the combinatorial PUI hydrogels demonstrate much higher toughness values than their comparable combinatorial photocrosslinked (CP) type equivalents. As discussed previously, this can likely be attributed to the well-defined poly(urethane-isocyanurate) network structure that is obtained by crosslinking using the trimerization of NCO-prepolymers [31]. For comparison, the mechanical characteristics of a selection of tough hydrogels reported in the literature are reported in Table 4. Both double network (DN) type hydrogels and combinatorial photocrosslinked (CP) type hydrogels are included. The highest ultimate tensile strengths and toughness values of the new PUI hydrogels lie in the same range as the PUUhydrogels reported by Yang et al., which are presently the toughest hydrogels reported in the literature [12]. Considering the relative simplicity and especially the versatility of the synthesis method reported here, combinatorial PUI hydrogels are considered a promising candidate for the future development of tough hydrogels and related biomaterials.

To investigate the effect of the swelling in water on the thermal properties of the combinatorial PUI hydrogels, we also performed DSC experiments in the water-swollen state (see Table 3). Interestingly, for all combinatorial hydrogels containing a crystallizable PCL prepolymer as the hydrophobic component (hydrogels $2 \mathrm{~W}, 3 \mathrm{~W}, 7 \mathrm{~W}$ and $8 \mathrm{~W}$ ) a melting peak was observed in the hydrated state. The melting peaks were all found in the range of $42{ }^{\circ} \mathrm{C}$ to $57^{\circ} \mathrm{C}$, which corresponds to the typical melting range of PCL domains within a PUI polymer network [31]. Significant melting enthalpies of $10-20 \mathrm{~J} / \mathrm{g}$ were measured for these hydrogels. As an example, the DSC heating curve of hydrogel $2 \mathrm{~W}$ in the hydrated state is shown in Fig. 2b, showing a clear semi-crystalline melting peak around $42.6^{\circ} \mathrm{C}$.

The observed melting peaks suggest that the segregated hydrophobic domains observed in the dry state remain intact when 
Table 3

Characterization of combinatorial PUI networks in the hydrated state. The prepolymers present in the networks (indicated by a gray box) are present in equal weight percentages. Numbers in parentheses represent standard deviations. Networks demonstrating a water uptake $>100 \%$ are defined as hydrogels and are marked in blue.

\begin{tabular}{|c|c|c|c|c|c|c|c|c|c|c|c|c|c|c|c|}
\hline \multirow{2}{*}{ 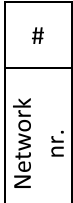 } & \multicolumn{7}{|c|}{$\begin{array}{c}\text { Network } \\
\text { Components }\end{array}$} & \multirow{2}{*}{$\begin{array}{c}\text { Swelling } \\
\text { Water } \\
\text { Uptake } \\
\text { [wt\%] }\end{array}$} & \multicolumn{3}{|c|}{ Thermal } & \multicolumn{4}{|c|}{ Tensile } \\
\hline & $\begin{array}{c}\text { y } \\
\text { ப́ } \\
\text { 㟧 }\end{array}$ & 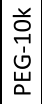 & 守 & 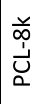 & 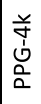 & $\begin{array}{l}\text { 首 } \\
0 \\
0 \\
\frac{0}{\alpha}\end{array}$ & 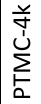 & & $\begin{array}{l}\mathrm{T}_{\mathrm{g} \text {,wet }} \\
{\left[{ }^{\circ} \mathrm{C}\right]}\end{array}$ & $\begin{array}{c}\mathrm{T}_{\mathrm{m}, \mathrm{p} \text {,wet }} \\
{\left[{ }^{\circ} \mathrm{C}\right]}\end{array}$ & $\begin{array}{c}\Delta \mathrm{H}_{\mathrm{m}} \\
{\left[\mathrm{J} \cdot \mathrm{g}^{-1}\right]}\end{array}$ & $\begin{array}{c}E_{\text {mod,wet }} \\
{[\mathrm{MPa}]}\end{array}$ & $\begin{array}{c}\sigma_{\mathrm{b}, \text { wet }} \\
{[\mathrm{MPa}]}\end{array}$ & $\begin{array}{c}\varepsilon_{\mathrm{b}, \mathrm{wet}} \\
{[\%]}\end{array}$ & $\begin{array}{c}\mathrm{W}_{\text {tensile,wet }} \\
{\left[\mathrm{MJ} \cdot \mathrm{m}^{-3}\right]}\end{array}$ \\
\hline $1 \mathrm{~W}$ & & & & & & & & $\begin{array}{l}1799.0 \\
(128.4)\end{array}$ & $-^{a}$ & $-^{a}$ & $-^{a}$ & $\begin{array}{c}0.5 \\
(0.3)\end{array}$ & $\begin{array}{c}0.03 \\
(0.01)\end{array}$ & $\begin{array}{c}87.8 \\
(32.0)\end{array}$ & $\begin{array}{c}0.02 \\
(0.01)\end{array}$ \\
\hline $2 W$ & & & & & & & & $\begin{array}{c}107.5 \\
(0.4)\end{array}$ & $-^{a}$ & 42.6 & 14.0 & $\begin{array}{l}10.1 \\
(1.9)\end{array}$ & $\begin{array}{c}7.7 \\
(1.9)\end{array}$ & $\begin{array}{c}624.0 \\
(250.7)\end{array}$ & $\begin{array}{c}33.2 \\
(14.3)\end{array}$ \\
\hline $3 W$ & & & & & & & & $\begin{array}{c}166.3 \\
(1.3) \\
\end{array}$ & $-^{a}$ & 57.0 & 14.5 & $\begin{array}{c}3.5 \\
(0.01) \\
\end{array}$ & $\begin{array}{c}1.0 \\
(0.1)\end{array}$ & $\begin{array}{l}122.0 \\
(32.5) \\
\end{array}$ & $\begin{array}{c}1.02 \\
(0.28) \\
\end{array}$ \\
\hline $4 W^{b}$ & & & & & & & & $-b$ & $-{ }^{b}$ & $-b$ & $-b$ & $-b$ & $-b$ & $-b$ & $-{ }^{b}$ \\
\hline $5 W^{b}$ & & & & & & & & $-b$ & $-{ }^{b}$ & $-b$ & $-b$ & $-b$ & $-b$ & $-b$ & $-b$ \\
\hline $6 W$ & & & & & & & & $\begin{array}{c}109.4 \\
(0.9)\end{array}$ & $-^{a}$ & $-{ }^{a}$ & $-^{a}$ & $\begin{array}{c}2.9 \\
(0.4)\end{array}$ & $\begin{array}{c}1.1 \\
(0.2)\end{array}$ & $\begin{array}{c}82.2 \\
(23.6)\end{array}$ & $\begin{array}{c}0.58 \\
(0.22)\end{array}$ \\
\hline $7 \mathrm{~W}$ & & & & & & & & $\begin{array}{c}154.0 \\
(4.4) \\
\end{array}$ & $-{ }^{a}$ & 44.5 & 16.9 & $\begin{array}{c}3.7 \\
(1.7) \\
\end{array}$ & $\begin{array}{c}4.1 \\
(0.5) \\
\end{array}$ & $\begin{array}{l}305.5 \\
(51.6) \\
\end{array}$ & $\begin{array}{c}8.89 \\
(2.23) \\
\end{array}$ \\
\hline $8 W$ & & & & & & & & $\begin{array}{c}287.9 \\
(2.4)\end{array}$ & $-^{a}$ & 56.7 & 10.8 & $\begin{array}{c}0.6 \\
(0.4)\end{array}$ & $\begin{array}{c}0.6 \\
(0.05)\end{array}$ & $\begin{array}{l}208.1 \\
(35.6) \\
\end{array}$ & $\begin{array}{c}0.96 \\
(0.19)\end{array}$ \\
\hline $9 W^{b}$ & & & & & & & & $-b$ & $-{ }^{b}$ & $-b$ & $-b$ & $-b$ & $-b$ & $-b$ & $-b$ \\
\hline $10 W^{b}$ & & & & & & & & $-b$ & $-^{b}$ & $-^{b}$ & $-{ }^{b}$ & $-b$ & $-{ }^{b}$ & $-{ }^{b}$ & $-b$ \\
\hline $11 W$ & & & & & & & & $\begin{array}{c}138.4 \\
(8.8)\end{array}$ & $-^{a}$ & $-{ }^{a}$ & $-{ }^{a}$ & $\begin{array}{c}2.7 \\
(0.1)^{d}\end{array}$ & $\begin{array}{c}0.9 \\
(0.2)^{d}\end{array}$ & $\begin{array}{c}135.5 \\
(49.9)^{d}\end{array}$ & $\begin{array}{c}0.86 \\
(0.45)\end{array}$ \\
\hline $12 W$ & & & & & & & & $\begin{array}{c}0.9 \\
(0.3)\end{array}$ & $-{ }^{a}$ & 58.6 & 87.8 & $\begin{array}{c}140.1 \\
(113.2)^{d}\end{array}$ & $\begin{array}{c}25.8 \\
(5.2)^{d}\end{array}$ & $\begin{array}{c}510.5 \\
(82.3)^{d}\end{array}$ & $\begin{array}{c}76.3 \\
(13.5)\end{array}$ \\
\hline $13 W^{b}$ & & & & & & & & $-{ }^{b}$ & $-{ }^{b}$ & $-{ }^{b}$ & $-{ }^{b}$ & $-{ }^{b}$ & $-{ }^{b}$ & $-{ }^{b}$ & $-^{b}$ \\
\hline $14 \mathrm{~W}$ & & & & & & & & $\begin{array}{c}1.1 \\
(0.1) \\
\end{array}$ & $-^{a}$ & 49.9 & 32.8 & $\begin{array}{l}37.9 \\
(2.2) \\
\end{array}$ & $\begin{array}{c}7.2 \\
(0.4) \\
\end{array}$ & $\begin{array}{l}295.4 \\
(54.7) \\
\end{array}$ & $\begin{array}{c}14.7 \\
(2.34) \\
\end{array}$ \\
\hline $15 W$ & & & & & & & & $\begin{array}{c}1.3 \\
(0.1)\end{array}$ & $-{ }^{a}$ & 44.6 & 36.5 & $\begin{array}{l}56.9 \\
(2.1)\end{array}$ & $\begin{array}{c}5.3 \\
(0.3)\end{array}$ & $\begin{array}{l}190.8 \\
(19.0)\end{array}$ & $\begin{array}{c}8.11 \\
(0.81) \\
\end{array}$ \\
\hline $16 \mathrm{~W}$ & & & & & & & & $\begin{array}{c}1.3 \\
(0.1)\end{array}$ & $-^{a}$ & 55.1 & 36.2 & $\begin{array}{l}38.2 \\
(2.7)\end{array}$ & $\begin{array}{c}5.9 \\
(0.6)\end{array}$ & $\begin{array}{l}162.9 \\
(28.2)\end{array}$ & $\begin{array}{c}7.57 \\
(1.44) \\
\end{array}$ \\
\hline $17 \mathrm{~W}$ & & & & & & & & $\begin{array}{c}1.7 \\
(0.4) \\
\end{array}$ & $-{ }^{a}$ & 54.4 & 42.2 & $\begin{array}{l}44.6 \\
(5.4) \\
\end{array}$ & $\begin{array}{l}12.9 \\
(0.6) \\
\end{array}$ & $\begin{array}{l}428.1 \\
(19.5)\end{array}$ & $\begin{array}{c}32.1 \\
(1.58) \\
\end{array}$ \\
\hline $18 \mathrm{~W}$ & & & & & & & & $\begin{array}{c}1.6 \\
(0.1)\end{array}$ & $-^{a}$ & 54.2 & 35.3 & $\begin{array}{l}19.5 \\
(1.8)\end{array}$ & $\begin{array}{c}3.7 \\
(0.3)\end{array}$ & $\begin{array}{l}55.9 \\
(9.6)\end{array}$ & $\begin{array}{c}1.42 \\
(0.30)\end{array}$ \\
\hline $19 W^{b}$ & & & & & & & & $-{ }^{b}$ & $-{ }^{b}$ & $-^{b}$ & $-{ }^{b}$ & $-^{b}$ & $-{ }^{b}$ & $-{ }^{b}$ & $-{ }^{b}$ \\
\hline $20 \mathrm{~W}$ & & & & & & & & $\begin{array}{c}2.4 \\
(1.1)\end{array}$ & $-^{a}$ & $-{ }^{a}$ & $-^{a}$ & $\begin{array}{c}1.6 \\
(0.6)^{d}\end{array}$ & $\begin{array}{c}0.8 \\
(0.1)^{d}\end{array}$ & $\begin{array}{c}134.7 \\
(40.5)^{d}\end{array}$ & $\begin{array}{c}0.71 \\
(0.25)\end{array}$ \\
\hline
\end{tabular}

${ }^{\text {a }}$ not observed.

${ }^{\mathrm{b}}$ macroscopic phase separation observed during crosslinking, resulting in a heterogeneous polymer film.

${ }^{\mathrm{c}} n=1$.

${ }^{\mathrm{d}} \mathrm{n}=2$.

Table 4

Characteristics of several tough hydrogel materials reported in the literature.

\begin{tabular}{|c|c|c|c|c|c|}
\hline \multirow[t]{2}{*}{ Hydrogel material } & \multirow{2}{*}{$\begin{array}{l}\text { Swelling } \\
\text { Water uptake [wt\%] }\end{array}$} & \multicolumn{4}{|l|}{ Tensile } \\
\hline & & $\mathrm{E}_{\text {mod,wet }}[\mathrm{MPa}]$ & $\sigma_{\mathrm{b}, \text { wet }}[\mathrm{MPa}]$ & $\varepsilon_{\mathrm{b}, \text { wet }}[\%]$ & $\mathrm{W}_{\text {tensile,wet }}\left[\mathrm{MJ} \mathrm{\textrm {m } ^ { - 3 } ]}\right.$ \\
\hline PDLLA-PCL-PEG CP ${ }^{\mathrm{a}}$ & $132(59)$ & $0.43(0.04)$ & $1.08(0.47)$ & $320(78)$ & $1.46^{\mathrm{b}}(0.71)$ \\
\hline PTMC-PDLLA-PCL-PEG CP & $181(2)$ & $1.49(0.38)$ & $1.81(0.31)$ & $283(60)$ & $-d$ \\
\hline PAMPS-PAAm DN ${ }^{e}$ & $900^{f}$ & $-{ }^{d}$ & 0.68 & 75 & $-d$ \\
\hline PDMAEA-Q/PNaSS DN ${ }^{g}$ & $73.9^{f}(7.4)$ & $7.9(0.6)$ & $5.1(0.6)$ & $750(80)$ & $18.8(1.9)$ \\
\hline Alginate-PAAm DN ${ }^{\mathrm{h}}$ & $614^{\mathrm{f}}$ & 0.029 & 0.156 & 2200 & $-{ }^{d}$ \\
\hline SA/PAMAAC JDN ${ }^{\mathrm{i}}$ & $567^{\mathrm{f}}$ & $-d$ & $1.8(0.03)$ & $655.7(26.7)$ & $-{ }^{d}$ \\
\hline PUU3-12 & $186^{\mathrm{f}}$ & 2.5 & 8.5 & 1000 & 45 \\
\hline Cartilage $^{\mathrm{k}}$ & 400 & 2.5 & 1.5 & 100 & $-{ }^{d}$ \\
\hline
\end{tabular}

a Data on a PDLLA-10k/PCL-4k/PEG-10k combinatorial photocrosslinked network (PDLLA-PCL-PEG CP) [10].

b Recalculated (and corrected) from original data.

c Data on a PTMC-4k/PDLLA-4k/PCL-4k/PEG-4k combinatorial photocrosslinked network (PTMC-PDLLA-PCL-PEG CP) [9].

d Data not reported.

e Data on a poly(2-acrylamido-2-methylpropanesulfonic acid)-poly(acrylamide) double network (PAMPS-PAAm) [25].

f Recalculated from original data.

g Data on an acryloyloxethyltrimethylammonium chloride-sodium p-styrenesulfonate (PDMAEA-Q/PNaSS) double network [28].

h Data on a calcium alginate/poly(acrylamide-acrylic acid) double network (Alginate-PAAm DN) [38].

i Data on a sodium alginate/poly(acrylamide-acrylic acid) joint double network (SA/PAMAAc JDN) [23].

j Data on a PEG-2k/IPDI Polyurethane-urea physical network (PUU3-12) [12].

k Data on patella cartilage [39]. 

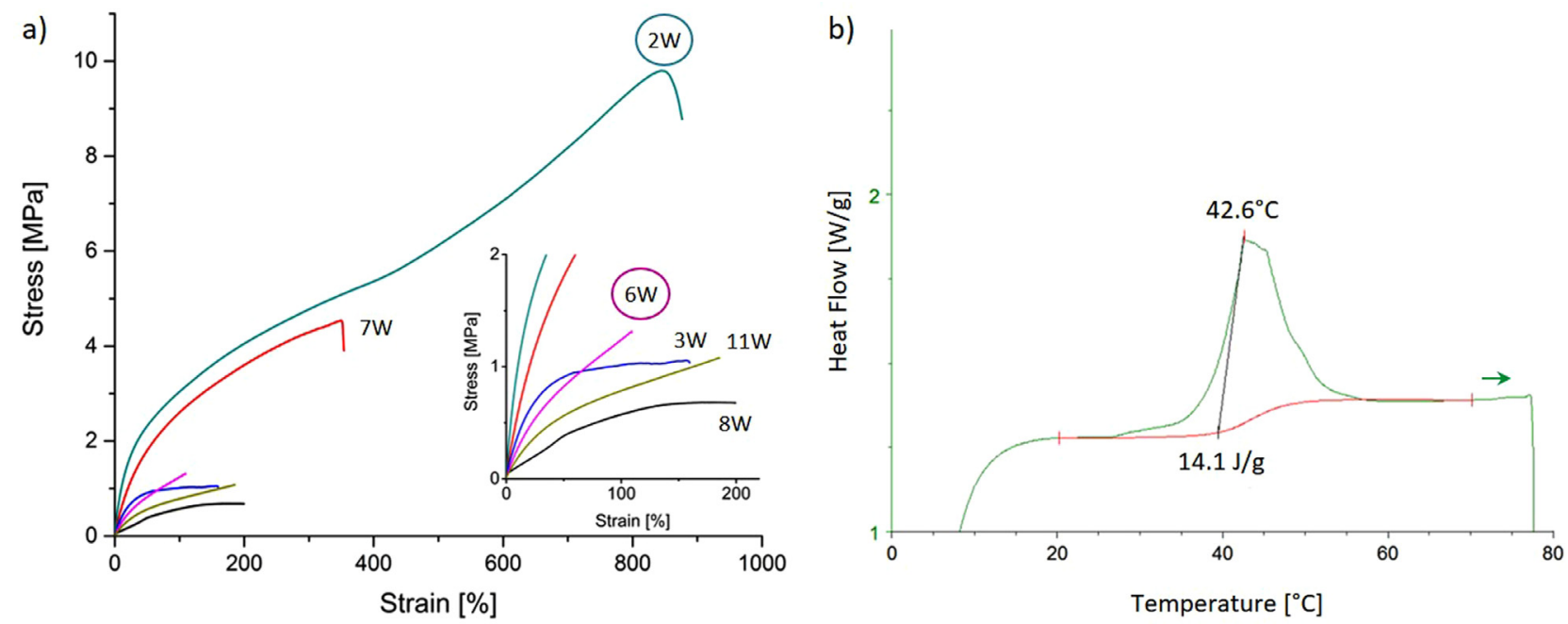

c)
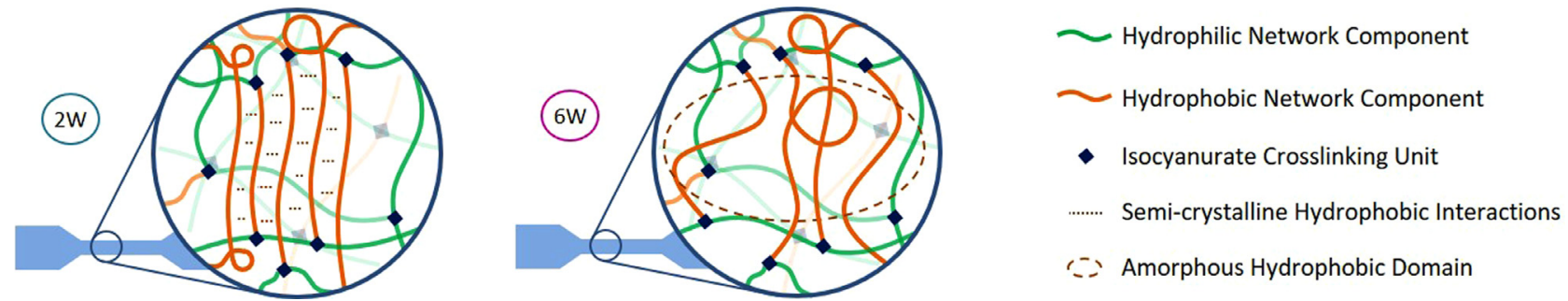

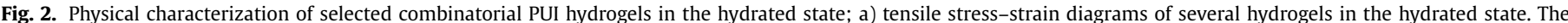

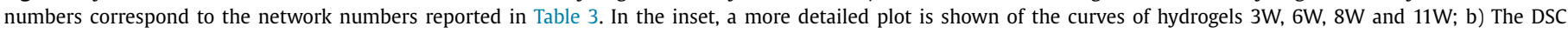

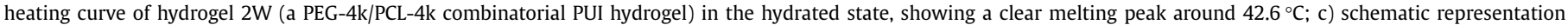

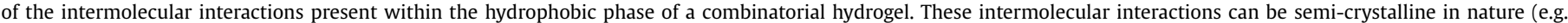
for hydrogel $2 \mathrm{~W}$, on the left) or amorphous in nature (e.g. for hydrogel $6 \mathrm{~W}$, on the right).

the combinatorial network is swollen in water. The presence of such segregated hydrophobic domains within a swollen hydrogel network has been reported in the literature before and has been correlated to a significant enhancement of the mechanical performance of a hydrogel $[17-21,40]$. The high toughness values and generally good mechanical properties of the combinatorial PUI hydrogels in the hydrated state can likely be attributed to this effect.

Segregated hydrophobic domains within swollen hydrogel networks can be either amorphous or semi-crystalline in nature. In the amorphous case, the intermolecular interactions between the hydrophobic network components are random and non-specific in nature, as sketched in Fig. 2c on the right side. The current PUI hydrogels containing an amorphous PPG- or PTMC prepolymer as the hydrophobic component (hydrogels $4 \mathrm{~W}, 5 \mathrm{~W}, 6 \mathrm{~W}, 9 \mathrm{~W}, 10 \mathrm{~W}$ and $11 \mathrm{~W})$ are also examples of such hydrogels. The mechanical performance of these hydrogels is better than that of single-network hydrogels, but is not exceptional.

In the combinatorial PUI hydrogels containing a crystallizable PCL prepolymer as the hydrophobic network component however, the segregated hydrophobic domains are semi-crystalline in nature. In these hydrogels $(2 \mathrm{~W}, 3 \mathrm{~W}, 7 \mathrm{~W}$ and $8 \mathrm{~W})$, the intermolecular interactions between the hydrophobic network components are wellordered and cooperative, as sketched in Fig. $2 \mathrm{c}$ on the left side. The presence of such crystalline domains is generally associated with a strong increase in the toughness of a material [41]. In fact, the combinatorial hydrogels containing a semi-crystalline PCL phase demonstrate the highest toughness values in the hydrated state of all combinatorial PUI hydrogels studied. The high toughness val- ues are likely attributable to the semi-crystalline nature of the hydrophobic domains of these hydrogels.

\subsection{Potential biomedical applications}

The PUI hydrogels developed in this work consist of chemical moieties that are known to be biocompatible or are expected to be biocompatible based on their chemical structure [34,42,43]. Also, comparable homopolymeric PEG-based PUI hydrogels have been shown to be biocompatible in indirect cytotoxicity studies [44]. Together with their water uptake, elastic moduli, ultimate tensile strength and toughness values in the water-swollen state, several of the new combinatorial PUI hydrogels are expected to be promising materials for biomedical applications.

The PUI hydrogels with a moderate water uptake (100$300 \mathrm{wt} \%$ ), high elastic modulus (>1 MPa) and high toughness values $\left(>1 \mathrm{MJ} \mathrm{m}^{-3}\right.$ ) are suitable for biomedical adhesive or coating applications [45]. In fact, considering that conventional PUI materials are well-established in the coatings and adhesives industry already, their potential application as biomedical adhesives and coatings is sensible [46]. These materials could be applied as coatings for catheter and cannula devices, coatings for suture materials and/or as direct tissue adhesives. The PUI hydrogels with high ultimate tensile strengths $(>1 \mathrm{MPa}$ ) and high toughness values ( $>1 \mathrm{MJ} \mathrm{m}^{-3}$ ) could be suitable for tissue engineering applications. Since the values reported here most closely represent natural cartilage and cardiovascular materials (see Tables 3 and 4), the synthesis of artificial substitutes for these materials seems most promising $[39,47]$. Upon further improvement of the tensile 
mechanical properties, also the synthesis of artificial tendons and/or ligaments might become possible in the future.

\section{Conclusions}

Combinatorial poly(urethane-isocyanurate) (PUI) polymer networks can be effectively synthesized by the trimerization of mixtures of NCO-functionalized PEG-, PCL-, PPG- and PTMC prepolymers. The resulting polymer networks demonstrate widely varying material properties in the dry state, highlighting the wide applicability and versatility of the synthesis method. Combinatorial networks consisting of two different crystallizable prepolymers demonstrate a double melting peak in the DSC experiments in the dry state, showing that two different network components are able to crystallize simultaneously within one combinatorial PUI network.

Combinatorial PUI networks containing at least one hydrophilic PEG component demonstrate high water uptake values of $>100$ wt\%. The resulting combinatorial PUI hydrogels exhibit high mechanical resilience in the water-swollen state. This is indicated by elastic moduli, ultimate tensile strengths, elongation at break values and toughness values of up to $10.1 \mathrm{MPa}, 9.8 \mathrm{MPa}, 624.0 \%$ and $53.4 \mathrm{MJ} \mathrm{m}^{-3}$, respectively. These values are considered very high and show that combinatorial PUI hydrogels are among the toughest hydrogels reported in the literature so far.

The presence of a hydrophobic network component in combinatorial PUI hydrogel networks is shown to enhance the toughness and tensile strength of the hydrogel in the hydrated state. This increase is the largest when the hydrophobic network component is crystallizable in nature. The combinatorial PUI hydrogels containing a crystallizable hydrophobic network component were semicrystalline in the water-swollen state. These hydrogels are expected to be promising materials for biomedical coating- and adhesive applications, as well as for tissue-engineering.

\section{Declaration of Competing Interest}

The authors declare that they have no known competing financial interests or personal relationships that could have appeared to influence the work reported in this paper.

\section{Acknowledgments}

This project has received funding from the European Union's Horizon 2020 research and innovation program under the Marie Skłodowska-Curie Grant Agreement no. 642890 (http:/I thelink-project.eu/).

The support of the labs of Dr. Frank Richter and the analytical departments of Covestro Deutschland AG Leverkusen is greatly acknowledged.

\section{Disclosure}

During the time of this research project, P.J. Driest and D.J. Dijkstra were employed by Covestro Deutschland AG.

\section{Supplementary materials}

Supplementary material associated with this article can be found, in the online version, at doi:10.1016/j.actbio.2020.01.025.

\section{References}

[1] A. Hoffman, Hydrogels for biomedical applications, Adv. Drug Deliv. Rev. 64 (2012) 18-23.
[2] N. Annabi, A. Tamayol, J.A. Uquillas, M. Akbari, L.E. Bertassoni, C. Cha, G. Camci-Unal, M.R. Dokmeci, N.A. Peppas, A. Khademhosseini, 25th Anniversary article: rational design and applications of hydrogels in regenerative medicine, Adv. Mater. 26 (2014) 85-124.

[3] Y. Liu, W. He, Z. Zhang, B. Lee, Recent developments in tough hydrogels for biomedical applications, Gels 4 (2018) 46.

[4] C. Creton, 50th Anniversary perspective: networks and gels: soft but dynamic and tough, Macromolecules 50 (2017) 8297-8316.

[5] J.P. Gong, Materials both tough and soft, Science 344 (2014) 161-162 80-

[6] J.P. Gong, Why are double network hydrogels so tough? Soft Matter 6 (2010) 2583-2590.

[7] Q. Chen, H. Chen, L. Zhu, J. Zheng, Fundamentals of double network hydrogels, J. Mater. Chem. B 3 (2015) 3654-3676.

[8] E. Zant, M.J. Bosman, D.W. Grijpma, Combinatorial synthesis of photo-crosslinked biodegradable networks, J. Appl. Biomater. Funct. Mater. 10 (2012) 197-202.

[9] E. Zant, D.W. Grijpma, Synthetic biodegradable hydrogels with excellent mechanical properties and good cell adhesion characteristics obtained by the combinatorial synthesis of photo-cross-linked networks, Biomacromolecules 17 (2016) 1582-1592.

[10] E. Zant, D.W. Grijpma, Tough biodegradable mixed-macromer networks and hydrogels by photo-crosslinking in solution, Acta Biomater. 31 (2016) 80-88.

[11] A. Güney, C. Gardiner, A. McCormack, J. Malda, D. Grijpma, Thermoplastic pcl-b-peg-b-pcl and hdi polyurethanes for extrusion-based 3D-printing of tough hydrogels, Bioengineering 5 (2018) 99.

[12] N. Yang, H. Yang, Z. Shao, M. Guo, Ultrastrong and tough supramolecular hydrogels from multiurea linkage segmented copolymers with tractable processablity and recyclability, Macromol. Rapid Commun. 38 (2017) 1-6.

[13] A.D. Drozdov, J.D. Christiansen, Nanocomposite gels with permanent and transient junctions under cyclic loading, Macromolecules 51 (2018) 1462-1473.

[14] R. Liu, S. Liang, X.-Z. Tang, D. Yan, X. Li, Z.-Z. Yu, Tough and highly stretchable graphene oxide/polyacrylamide nanocomposite hydrogels, J. Mater. Chem. 22 (2012) 14160

[15] F.A. Aouada, M.R. de Moura, W.J. Orts, L.H.C. Mattoso, Preparation and characterization of novel micro- and nanocomposite hydrogels containing cellulosic fibrils, J. Agric. Food Chem. 59 (2011) 9433-9442.

[16] Y. Okumura, K. Ito, The polyrotaxane gel : a topological gel by figure-of-eight cross-links, Adv. Mater. 13 (2001) 485-487.

[17] A. Argun, D.C. Tuncaboylu, M. Sari, O. Okay, M. Sahin, Structure optimization of self-healing hydrogels formed via hydrophobic interactions, Polymer 53 (2012) $5513-5522$.

[18] Y. Zhang, Y. Li, W. Liu, Dipole-dipole and h-bonding interactions significantly enhance the multifaceted mechanical properties of thermoresponsive shape memory hydrogels, Adv. Funct. Mater. 25 (2015) 471-480.

[19] H. Guo, N. Sanson, D. Hourdet, A. Marcellan, Thermoresponsive toughening with crack bifurcation in phase-separated hydrogels under isochoric conditions, Adv. Mater. 28 (2016) 5857-5864.

[20] H.J. Zhang, F. Luo, Y. Ye, T.L. Sun, T. Nonoyama, T. Kurokawa, T. Nakajima, Tough triblock copolymer hydrogels with different micromorphologies for medical and sensory materials, ACS Appl. Polym. Mater. 1 (2019) 1948-1953.

[21] H. Jiang, L. Duan, X. Ren, G. Gao, Hydrophobic association hydrogels with excellent mechanical and self-healing properties, Eur. Polym. J. 112 (2019) 660-669.

[22] J. Yang, Y. Li, L. Zhu, G. Qin, Q. Chen, Double network hydrogels with controlled shape deformation : a mini review, J. Polym. Sci. Part B Polym. Phys. 56 (19) (2018) 1351-1362.

[23] M. Zhang, X. Ren, L. Duan, G. Gao, Joint double-network hydrogels with excellent mechanical performance, Polymer 153 (2018) 607-615.

[24] J.P. Gong, Why are double network hydrogels so tough, Soft Matter 6 (2010) 2583

[25] J.P. Gong, Y. Katsuyama, T. Kurokawa, Y. Osada, Double-network hydrogels with extremely high mechanical strength, Adv. Mater. 15 (2003) 1155-1158.

[26] M.A. Haque, T. Kurokawa, J.P. Gong, Super tough double network hydrogels and their application as biomaterials, Polymer 53 (2012) 1805-1822.

[27] T.T. Mai, T. Matsuda, T. Nakajima, J.P. Gong, K. Urayama, Distinctive characteristics of internal fracture in tough double network hydrogels revealed by various modes of stretching, Macromolecules 51 (2018) 5245-5257.

[28] F. Luo, T.L. Sun, T. Nakajima, T. Kurokawa, Y. Zhao, K. Sato, A.Bin Ihsan, X. Li, H. Guo, J.P. Gong, Oppositely charged polyelectrolytes form tough, self-healing, and rebuildable hydrogels, Adv. Mater. 27 (2015) 2722-2727.

[29] E.S. Dragan, Design and applications of interpenetrating polymer network hydrogels. A review, Chem. Eng. J. 243 (2014) 572-590.

[30] E. Zant, M.M. Blokzijl, D.W. Grijpma, A combinatorial photocrosslinking method for the preparation of porous structures with widely differing properties, Macromol. Rapid Commun. 36 (2015) 1902-1909.

[31] P.J. Driest, D.J. Dijkstra, D. Stamatialis, D.W. Grijpma, The trimerization of isocyanate-functionalized prepolymers : an effective method for synthesizing well-defined polymer networks, Macromol. Rapid Commun. 40 (2019) 1800867.

[32] B.E. Read, Mechanical relaxation in some oxide polymers, Polymer 3 (1962) $529-542$

[33] F.E. Bailey, E. Frederick, J.V. Koleske, Poly(ethylene Oxide), Academic Press, 1976.

[34] A.P. Pêgo, A.A. Poot, D.W. Grijpma, J. Feijen, Copolymers of trimethylene carbonate and $\varepsilon$-caprolactone for porous nerve guides: synthesis and properties, J. Biomater. Sci. Polym. Ed. 12 (2001) 35-53. 
[35] J.A. Faucher, The dependence of glass transition temperature on molecular weight for poly(propylene oxide) and poly(butylene oxide), J. Polym. Sci. Part B Polym. Lett. 3 (1965) 143-145.

[36] A.P. Pêgo, D.W. Grijpma, J. Feijen, Enhanced mechanical properties of 1,3-trimethylene carbonate polymers and networks, Polymer 44 (2003) 6495-6504.

[37] J. Li, W.R.K. Illeperuma, Z. Suo, J.J. Vlassak, Hybrid hydrogels with extremely high stiffness and toughness, ACS Macro Lett. 3 (2014) 520-523.

[38] J.-Y. Sun, X. Zhao, W.R.K. Illeperuma, O. Chaudhuri, K.H. Oh, D.J. Mooney, J.J. Vlassak, Z Suo, Highly stretchable and tough hydrogels, Nature 489 (2012) 133-136.

[39] M.V. Chin-Purcell, J.L. Lewis, Fracture of articular cartilage, J. Biomech. Eng. 118 (1996) 545.

[40] M.A. Przeradzka, B. van Bochove, T.C. Bor, D.W. Grijpma, Phase-separated mixed-macromer hydrogel networks and scaffolds prepared by stereolithography, Polym. Adv. Technol. 28 (2017) 1212-1218.
[41] A. Galeski, Strength and toughness of crystalline polymer systems, Prog. Polym. Sci. 28 (2003) 1643-1699.

[42] G. Liu, Y. Li, L. Yang, Y. Wei, X. Wang, Z. Wang, L. Tao, Cytotoxicity study of polyethylene glycol derivatives, RSC Adv. 7 (2017) 18252-18259.

[43] F. Burel, L. Poussard, M. Tabrizian, Y. Merhi, C. Bunel, The influence of isocyanurate content on the bioperformance of hydrocarbon-based polyurethanes, J. Biomater. Sci. Polym. Ed. 19 (2008) 525-540.

[44] P.J. Driest, I.E. Allijn, D.J. Dijkstra, D. Stamatialis, D.W. Grijpma, Poly(ethylene glycol)-based poly(urethane isocyanurate) hydrogels for contact lens applications, Polym. Int. (2019), doi:10.1002/pi.5938.

[45] S. Fuchs, K. Shariati, M Ma, Specialty tough hydrogels and their biomedical applications, Adv. Healthc. Mater. 1901396 (2019) 1-33.

[46] U. Meier-Westhues, K. Danielmeier, P. Kruppa, E.P. Squiller, Polyurethanes Coatings, Adhesives and Sealants, Vincentz-Network Verlag, 2019.

[47] D.L. Taylor, M. In Het Panhuis, Self-healing hydrogels, Adv. Mater. 28 (2016) 9060-9093. 